\title{
ABAS-3 - AN INSTRUMENT FOR ASSESSING ADAPTIVE SKILLS IN PEOPLE WITH AN INTELLECTUAL DISABILITY
}

\author{
ANNA PROKOPIAK ${ }^{1}$, JANUSZ KIRENKO ${ }^{1}$ \\ ${ }^{1}$ Maria Curie-Sklodowska University, Lublin, Poland, contact: aniaprokopiak@wp.pl
}

Received: 25.03.2020.

Preliminary report

Accepted: 10.11.2020.

UDK: $159.9 .072-056.3$

doi: $10.31299 /$ hrri.56.2.9

\begin{abstract}
In its initial part, the article presents an analysis of the definition of intellectual disability and follows its development over the past half century. In order to diagnose an intellectual disability, it is important not only to demonstrate an overall level of intelligence that is at least two standard deviations below the median score, but also to take into account the concurrent criterion of developmental age. Moreover, as discussed in this article, defining an intellectual disability also requires addressing limitations in adaptive behaviour, i.e. cognitive, social and practical functioning skills. These diagnostic criteria are met by the "Adaptive Behavior Assessment System" (ABAS), published originally in 2000 by Harrison and Oakland. Its third edition came out in 2015. ABAS-based evaluations find a wide variety of uses, including assessing adaptive behaviour of people with intellectual disabilities, diagnosing and classifying disabilities and disorders, documenting and monitoring progress over time, and determining entitlement to disability benefits. The instrument has many strengths, but it also exhibits limitations. For example, comprehensive examination is only possible if the localised adaptations of ABAS are suited for people in the age bracket of 0-89 years. The effective use of this instrument is also dependent on its compatibility with the formal disability assessment system and with the strategies for working with students who have intellectual disabilities. The level of this compatibility should be no less than the American variant. Only then will ABAS-3 be fully adaptable to the purpose for which the assessment is developed, and the results obtained will be useful and properly applied.
\end{abstract}

Key words: intellectual disability, adaptive skill assessment, ABAS-3

\section{WHY WAS THIS STUDY DONE?}

The aim of the article is to analyse the potential of the ABAS-3 tool on the basis of the experience of its application in Poland. The currently prevalent model shows that intellectual disability manifests itself in a dynamic, mutual relationship involving intellectual capacity, adaptability, health, participation, context and individualised support measures. It is a specific human condition that arises during childhood, where a significantly lower than average level of overall intellectual functioning coexists with limitations on adaptability. None of the tools previously known measured all the adaptive skills included in the definition of intellectual disability, until the Adaptive Behaviour Assessment System (ABAS) was published.

\section{WHAT DID THE RESEARCHERS DO?}

After a thorough exploration of how the concept of intellectual disability developed in the literature of the subject, the authors strive to demonstrate that only the ABAS-3 tool reflects current standards for characterising adaptive behaviour and for diagnosing the conditions under which it can be affected in people with intellectual disabilities. The analysis of the Polish adaptation of ABAS-3 leads to recommendations of measures to ensure that the ABAS-3 assessment is used throughout the lifespan of an examined person, which allows planning both individual and systemic solutions.

\section{WHAT DO THESE FINDINGS ADD TO WHAT WAS ALREADY KNOWN?}

The described results of the analysis of how ABAS-3 has been adapted in Poland may facili- 
tate both the preparation of new adaptations (localisations) and the future use of this tool in other European countries, including Croatia.

\section{INTRODUCTION}

The adequacy of a concept used to describe a given social phenomenon is influenced by many factors; such a concept should therefore generally refer to the human being with his or her needs and be applied consistently according to public and research interests. It is also important that this concept should reflect the current state of research, thus creating opportunities for its use in various areas, e.g. diagnostics, classification or planning of services etc. Moreover, through its operability, this concept should reflect the specificity of the group researched (Luckasson \& Reeve, 2001).

Undoubtedly, these criteria are met by the currently used concept of intellectual disability, also referred to as mental disability. This concept is used to describe a disposition that has its origins in a health condition - a disorder or illness - causing impairment of the functioning of the body and its structure, limiting the ability to act in the context of personal and environmental factors (International Classification of Functioning, Disability and Health 2001; see: Luckasson et al., 2002; Browder et al., 2007, J. Douma et al., 2007; Cooper et al., 2007; also see: Kirenko \& Łaba-Horecka, 2018).

\section{THE HISTORICAL CONTEXT}

The way in which the definition of intellectual disability has been used in research discourse over time allows a conclusion that the concept has evolved towards an ecological perspective. It is becoming gradually person-centred and environmentally oriented. It has also developed a clear focus on systematic, individualised forms of interaction with a person with disabilities, which are to enhance his or her functioning. Structurally, the definition of intellectual disability focuses on deficits in particular areas of functioning, particularly in the social sphere. This definitional structure is to a large extent justified by numerous research reports on the social construction of illness, and the related impact of social attitudes, roles and principles (Aronowitz, 1998). It also reflects the gradual elimination of the traditional distinction between biological and social causes of disability (Institute of Medicine, 1991), and it shows the recognition and acknowledgement of the multidimensionality of human functioning (Luckasson et al., 2002). Achievements in the above-mentioned areas resulted in a modified approach to defining intellectual disabilities (Luckasson et al. 2002; also see: Kirenko \& Łaba-Horecka, 2018). In many research debates concerning how to name the phenomena at hand it was argued that the classical concept of mental retardation ignored elements of human dignity (Finlay \& Lyons, 2005; Hayden \& Nelis, 2002; Rapley, 2004; Snell \& Voorhees, 2006; Polloway et al., 2009). The decision to express the concept under analysis as intellectual disability also resulted from the change in the understanding of the concept of disability itself, as defined by the American Association on Intellectual and Developmental Disabilities (AAIDD). The new concept focuses on functional behaviour, contextual factors and on providing a rational basis for the provision of individualised services and support. The new concept is also considered less offensive to people with disabilities and more in line with international terminology. Definitions provided by the American Association of Mental Retardation (AAMR) are generally compatible with the definitions provided by the American Psychiatric Association (APA). Thus, with AAMR, the defining efforts started with Heber's definition of 1959, where mental retardation referred to general intellectual functioning and related disorders in one or more areas, including: growth, learning outcomes and social adjustment. This was followed by another definition by Heber, proposed in 1961, which referred to general intellectual functioning during the developmental period and related disorders in adaptive behaviours. The subsequent definitions were developed by Grossman in 1973 and 1983, in which the notion of mental impairment is used to refer to general intellectual functioning and related disorders in adaptive behaviours that appear during the developmental period. More contemporary definitions were proposed by Luckasson et al. in 1992, with their traditional understanding of deficits in general intellectual functioning. These were followed by newer concepts of functioning in two or more skill areas such as: communication, self-care, home liv- 
ing, social skills, being socially useful, self-direction, health and safety, school functioning, leisure and work - all of which appear by the age of 18 . Here the proposals developed by Luckasson et al. in 2002 are also relevant (also see: Meijer et al., 2004; Myrbakk \& Von Tetzchner, 2008; Patton \& Keyes, 2006; Perske, 2005, 2008; Goodey, 2006; Schalock et al., 2010). As mentioned above, all these are generally consistent with the definitions by APA in their respective versions: DSM-II (1968), DSM-III (1980), DSM-III-R (1987), DSMIV (1994), DSM-TR (2000) (after Schalock et al., 2010) and DSM-5. According to the latest diagnostic criteria (DSM-5), published in 2013, intellectual disability is a group of disorders that have their onset early in the developmental period. Their occurrence is caused by many non-heterogeneous factors. Intellectual disability can be associated with difficulties in expressing adequate and socially accepted opinions, inappropriate behaviour, poor emotional control or inadequate response to environmental signals, as well as a general lack of motivation to act. The flawed communication skills of some persons may predispose them to disruptive and aggressive behaviours. Such persons can exhibit gullibility and naivety in social situations (Diagnostic and Statistical Manual of Mental Disorders Fifth Edition DSM-5, American Psychiatric Association 2013; also see: Kirenko \& Łaba-Horecka, 2018).

\section{CURRENT APPROACHES TO INTELLECTUAL DISABILITY}

Analysing the definitions of intellectual disability developed over the past five decades, one can conclude that its three basic defining criteria have not changed significantly over time: deficits in intellectual functioning, impaired adaptation to the requirements of the environment, and the early-age onset of the disorders. One can also observe that the two abovementioned definitions from the AAMR/ AAIDD and APA remain operational (Denning et al., 2000; Bach, 2007; Brown, 2007; Polloway et al., 2010; Kirenko \& Łaba-Horecka, 2018).

At the same time, our explorations of terminology relating to intellectual disability allows us to put forward the following five main assumptions, which demonstrate essentially how the definition of intellectual disability is practically applied:

1. The currently observed functional limitations should be approached in the context of environmental culture and age (Schalock et al., 2010, p. 7), which means that the standards of individual functioning are compared against the norms of typical local communities, i.e. home, neighbourhood, schools, businesses and other environments, in which people are similar in terms of age, play, work and interaction.

2. Evaluation of functioning also covers cultural and linguistic diversity, as well as differences in communication, sensory perception and psychomotor behaviours (Schalock et al., 2010, p. 7). Assessment is valid only if it accounts for individual diversity. Individual cultural background and ethnicity (including the language that an individual speaks in the home) as well as non-verbal communication can influence the assessment, and should therefore be taken into account in approaching a person's functioning (Schalock et al., 2010).

3. Limitations in individuals often coexist with strengths (Schalock et al., 2010, p.7), which means that people with intellectual disabilities are fully human in having both strong points as well as limitations. Like most people, they do certain things better than others. They have their own abilities and strengths, irrespective of their intellectual disabilities (Schalock et al., 2010).

4. A particularly important aim of describing limitations is to develop the profile of support needed (Schalock et al., 2010, p. 7). This means that focusing solely on the limitations is insufficient. Rather, the limitations should mark a first step in developing theory and practice of support for individuals with intellectual disabilities in order to improve their functioning (Schalock et al., 2010).

5. With appropriate personalised support provided over a sustained period, the life of an individual with intellectual disability will definitely improve (Schalock et al., 2010, p. 7). The lack of observed improvement in functioning may suggest a need to modify the profile of assistance. In some rare cases, adequate support 
can only help maintain a certain level of proper functioning or put off regression. Most importantly, adequate support falsifies the stereotype that people with intellectual disabilities cannot improve their functioning (Schalock et al. 2010; also see: Kirenko \& Łaba-Horecka, 2018).

Research on the concept of human functioning led scholars to postulate a multidimensional model. It was proposed by the American Association on Intellectual and Developmental Disabilities (AAIDD), formerly the American Association of Mental Retardation (AAMR), in their 1992 manual (Luckasson et al., 1992), with later revision in the 2002 manual (Luckasson et al., 2002). The proposed model refers to five dimensions of human functioning (intellectual capacity, adaptive behaviour, health, social participation and context) and support measures that can help improve it. The model shows that intellectual disability manifests itself in a dynamic, reciprocal relationship involving intellectual capacity, adaptive behaviour, health, social participation, context and individualised support measures. The assumptions of the model are consistent with the International Classification of Functioning, Disability and Health (Kirenko \& Łaba-Horecka, 2018). According to the model, the concept of human functioning is an umbrella term for all life activities. It covers the structure and functions of the body, human actions and social participation, which in turn are determined by health as well as environmental and contextual factors. Limitations in functioning are referred to as "impairment", which may result from a problem or problems with either the structure or the functioning of the human body. Furthermore, the functional domains (intellectual impairment) and action areas (impaired adaptive behaviours) defined in this model rely on the diagnostic criteria proposed under the functional approach to mental disability (Schalock et al., 2010). Thus, they highlight five essential dimensions of human functioning, in contrast to the four dimensions listed in the 1992 AAIDD manual.

\section{DOMAINS OF HUMAN FUNCTIONING}

The first domain consists of mental abilities, such as reasoning, planning, problem solving, abstract thinking, complex conceptualisations, efficient learning and learning from experience (Gottfredson, 1997). Intelligence is not only about narrowly understood academic or test-solving skills. Intelligence reflects a wider and deeper potential for understanding the human environment. Therefore, the notion of intelligence expresses an attempt to explain and categorise differences in the ability to understand complex concepts, to effectively adapt to the environment, to learn from our own experiences, to make various attempts at reasoning and to overcome obstacles through reasoning and communication (Neisser et al., 1996). Understood in this way, the notion of intelligence was first used in the AAMR/AAIDD textbook published in 1983 by H.J. Grossman. This notion of intelligence is also consistent with the definition of intellectual functions proposed in the International Classification of Functioning, Disability and Health. These functions are understood as general mental abilities necessary to understand and constructively integrate various functions, including cognitive ones. It also assumed that these functions develop throughout a lifetime (WHO 2001, section b 117; Schalock et al., 2010). The second domain is composed of adaptive behaviours, i.e. a network of conceptual, social and practical skills that a person has learned and puts to regular use. The notion of adaptive behaviour marks a continuation of the classical theoretical approach that paid attention to adaptive behaviour in the diagnosis of developmental impairments/mental disabilities (Schalock et al., 2007). The third domain of the presented model of intellectual disability is health, understood as general well-being and mental health, which affects the functioning of the body. Some people with intellectual disabilities enjoy good health and are not affected by significant activity restrictions. This allows them to fully participate in social roles at work and in leisure time. However, there are also those who face significant health problems, such as epilepsy or cerebral palsy, which impair the functioning of their bodies in areas such as mobility or nutrition, and which significantly affect their functioning and social participation (Schalock et al., 2010). The fourth domain of the discussed definition of intellectual disability is social participation, which constitutes a key factor in a person's learning process (Dunst et al., 2006). Social participation refers to roles and interactions in the areas 
of home life, work, education, leisure, religion and culture. It also includes social roles as crucial components of the functioning of social groups. Participation is best assessed through direct observation of involvement and degree of inclusion in everyday functioning (Schalock et al., 2010). The final domain to consider is the context in which the interrelated conditions of an individual's daily life are assessed. The notion of context reflects an ecological perspective on human functioning and its three levels (U. Bronfenbrenner, in: Schalock et al., 2010):

1. the immediate social environment, the individual person and his or her family or carers (microsystem);

2. the neighbourhood, community or organisations providing education or support measures (mesosystem); and

3. cultural, traditional and national patterns (macrosystem) (also see: Kirenko \& ŁabaHorecka, 2018).

Under the functional model, intellectual disability is therefore a specific human condition that arose during childhood, in which a significantly lower than average level of overall intellectual functioning overlaps with limitations in adaptive behaviour. It is a condition in which the current, observable functioning of an individual is limited, but this condition cannot be understood in terms of a personality trait. This is a vital point, because examining a person for a mental disability cannot focus on personality traits but should aim at understanding their current functioning in everyday life (Luckasson et al., 1992; Kostrzewski, 1997). According to Kostrzewski (1997), each person is uniquely complex. Therefore, an investigator should adopt a combined approach, where profound knowledge about disabilities is accompanied by the fine art of gaining comprehensive insights into a person. Thus, the investigator's aim is to precisely and comprehensively determine the general level of intellectual functioning, the adaptive behaviour, the emotional and motivational sphere, personality traits, social roles played, health status, reasons for the current state of affairs, the functional environment and its requirements, as well as all strengths and weaknesses.

\section{CHALLENGES FOR PRACTICE}

Consequently, Schalock et al. (2010) argue that the examination and assessment be carried out with the aim of providing a diagnosis, categorisation and support system for people with intellectual disabilities. They also recommend that the assessment be conducted in relation to the individual characteristics of each person, in the specific areas of his or her functioning. To do that, three criteria must be met:

1. the assessment instrument and procedures must be adapted precisely to the purpose of assessment,

2. the results must have the best possible validation, and

3. the results must meet the criterion of usability and must be properly applied.

In 2002, the AAIDD proposed an assessment scheme structured around three functions: diagnosis, classification and planned support (Luckasson et al., 2002). The AAIDD experts pointed out that the assessment instruments and results can be useful for certain social groups, but not necessarily all groups. The previous version of the AAIDD manual (Luckasson et al., 1992) critically approached the four-level classification of intellectual disabilities (mild, moderate, severe, profound), arguing that it takes into consideration only IQ test results. A classification of that kind can be useful for research purposes, where the measured intelligence is an significant variable, but it fails as a parameter in deciding on a person's life, e.g. allowing him or her to stay at home, directing the individual to a particular type of care facility, or deciding on his or her education - inclusive, integrative or segregative (Schalock et al., 2010; Kirenko \& Łaba-Horecka, 2018).

Data on people with intellectual disabilities can be classified differently for many different reasons, such as research, development of support services or their financing. Practitioners in the field of intellectual disabilities should choose a classification system that is consistent with their objectives, and they should use it only to provide relevant services. There are many classification systems available in research sources and applied on daily basis, devoted to assessing adaptive behaviour, intellectual functioning, educational needs and individu- 
alised needs for support. According to Schalock et al. (2010), to provide correct assessment and classification of intellectual disabilities, the classification systems must rely on solid evidence proving that the classification will benefit everyone in the group. An individualised planning process is important here, focusing on specific aspects of improved performance or improved outcomes, which should integrate assessment results obtained both in a standardised way and through informal measures (cf. Kirenko \& Łaba-Horecka, 2018).

In order to diagnose intellectual disabilities, it is therefore important to demonstrate not only an overall level of intelligence that is at least two standard deviations lower, but also the co-occurrence of the criterion of developmental age. As suggested in the present article, it is equally vital to prove the limitations of adaptive behaviour, i.e. cognitive, social and practical skills. According to Luckasson et al. (2002), "adaptive behaviour is a set of cognitive, social and practical skills that people have mastered in order to function in everyday life" (p. 11). Limitations in adaptive behaviour should be analysed taking into account mental abilities, social participation, interactions, social roles performed, as well as the state of health and the circumstances of the educational and social environment. They should be determined using reliable and valid measurement tools, standardised on a representative sample. To talk about disability, the level of measured adaptive behaviour must be lower than the average by two standard deviations (Luckasson et al., 2002; Kostrzewski, 2006).

\section{DEMAND FOR A NEW ASSESSMENT TOOL}

The definition of intellectual disability proposed by the AAMR in 1992 as deficits in at least two of the 10 skills listed did not explain whether the skills were all correlated or not, which could lead to serious interpretation problems. Likewise, the lack of appropriate measurement instruments for these skills was problematic. Out of over 130 tools for assessing adaptive behaviour available in Poland, the following were the most popular: "PAC Inventory" (Progress Assessment Chart), including the PPAC, PAC-1, PAC-2 and PAS (Personal Assessment Scale) by H.C. Gunzburg of 1974 (see: Witkowski, 1997); the "Children,
Youth and Adults Adaptative Behaviour Scale" by Nihira, Foster, Shellhaas and Leland in 1975; the "Vineland Adaptative Behaviour Scale" (Sparrow \& Chichetti, 1985); and a modernised and revised version of the "Social Maturity Scale" by E.A. Doll of 1964 (see: Kostrzewski, 1997). None of these tools covers assessment of all adaptive behaviours. The first tool to cover them all is the ABAS, developed by Harrison and Oakland in 2002. This instrument is used to assess adaptive behaviour and the related cognitive, social and practical skills. The second edition of ABAS (ABAS-II) was published in 2003, and the third (ABAS-3) in 2015. In the introduction to the latest version, Harrison and Oakland wrote that the instrument retains "all the essential features of ABAS-II and has numerous improvements" (p. 1).

ABAS-3 reflects current standards for describing adaptive behaviour and for diagnosing the conditions under which it can be disturbed. This is why "it offers a comprehensive, standardised system for assessing the adaptive skills needed to effectively and independently care for one's own needs, respond to other people and meet the requirements of the environment at home, at school, at work and in the local community" (p. 1). Parents, teachers, family members and caregivers of the assessed persons and the persons themselves fill in a form which, after calculation and interpretation of the results by the investigator, gives insight into the adaptive behaviour of the assessed person, as measured against a normative group of peers in a given population. The instrument can be used in a printed form, or via the English-language WPS Online Evaluation System. It can be applied in the age bracket of 0-89 years in different social environments such as nurseries, schools, hospitals, nursing homes, and care centres.

The results obtained on the ABAS- 3 can be used in many ways, including:

1. help in diagnosing and classifying developmental and behavioural disorders (e.g. intellectual disorders, difficulties in learning, behavioural or emotional disorders),

2. help in identification of limitations in functioning behaviour in children and adults displaying a variety of difficulties and disorders (e.g. ASD, ADHD, Alzheimer's), 
3. document-based qualification of a person for therapeutic or educational programmes and activities (e.g. in special education, social assistance, or treatment),

4. help in planning and monitoring treatment to improve the adaptive skills and daily functioning of the assessed person, and

5. help in research on the evaluation of therapies and treatment outcomes.

\section{THE STRUCTURE OF ABAS-3}

ABAS-3 consists of five forms that require elementary reading skills. The first form is dedicated to the parent or the primary carer of children aged between 0 years and 5 years, 11 months. It examines the adaptive skills of newborns, toddlers and pre-schoolers in the home and in other familiar surroundings. It may also be completed by parents or other primary caregivers. The second form - for a parent - examines the adaptive skills of children and young people at home and in other settings they find familiar. It may be completed by parents or other primary caregivers. It is dedicated to children and youth between ages 5 and 21 and 11 months. This wide age bracket allows participation of students in special schools. The third form is dedicated to the teacher or day-care provider of children aged from 2 years to 5 years, 11 months. It is used to assess adaptive skills in young children and pre-schoolers in day-care centres, in home care, in nurseries or at school. It can also be completed by teachers, support teachers or other persons providing care for children. The fourth form - for a teacher - is used to assess children and young people aged from 5 years to 21 years, 11 months, who stay at school. It can also be completed by teachers, support teachers or other school staff. The form applies to persons up to 21 years of age. The last form is prepared for people aged 16 years to 89 years, 11 months. It examines adults' adaptive skills in the home and in other familiar surroundings. It can be completed by family members, superiors or other persons who know the person being assessed well. It can also be completed by the person himor herself, so long as his or her functional skills allow him or her to give authentic answers to the questions. The form has two separate tables with norms - one for assessment by the others and one for self-assessment (Harrison \& Oakland, 2015).

The investigators carrying out an assessment examine the content provided by the respondents in order to determine whether an assessed person is capable of a given adaptive behaviour. If the person is, and if necessary, the investigators can also determine how often a given adaptive behaviour can be observed ("never", "sometimes" or "almost always"). The investigators can also assess a given behaviour by drawing on a smaller amount of information, in which case, however, they must note that their findings are only a presupposition. Information collected from many investigators leads to a better understanding of an individual's adaptive behaviour. Therefore, it is recommended that forms be completed by two or more people at a time. Since filling in one form takes no more than 20 minutes, collecting the data from more than one person is not exhaustive.

Adaptive behaviour is assessed on three different levels. The highest level is called General Adaptive Composite (GAC). It covers all the examined skill areas and allows for a comprehensive assessment of adaptive behaviour. At the next level, there are three Adaptive Domains, consisting of several skill areas:

- conceptual - skills needed to communicate with others, use knowledge as well as manage and successfully complete tasks;

- social - skills needed to engage in interpersonal relations, to take up social responsibility and to manage leisure time;

- practical - skills needed to take care of personal and health needs, to take care of the home, classroom or workplace and to function in society.

The third level is occupied by individual adaptive skills, such as communication, social skills, practical learning, home/school life, health and safety, leisure time, self-care, self-direction, socialising, work (for young people and working adults) and psychomotor activity (for young children) (Harrison \& Oakland, 2015).

The assessment obtained is compared against the results recorded for the peers in the standardisation samples. The results for the General Adaptive Composite and for Adaptive Domains include standardised results $(M=100, S D=15)$, confidence 
intervals for standardised results and percentile ranks. The results for the individual areas of adaptive skills are converted values $(\mathrm{M}=10, \mathrm{SD}=3)$. The descriptive classification (very low, low, below average, average, above average and high) may be applied to the GAC, adaptive domains and adaptive skill areas to facilitate the interpretation of results by expressing the numerical ranges in a descriptive formulation (Harrison \& Oakland, 2015).

In all five forms, the GAC covers all areas of adaptive skills, except for e.g.: practical learning, social functioning and home activities, which are not assessed for children under the age of one. The psychomotor skills are only included in the form for the parent or primary carer (Form 1) as well as for the teacher or day-care provider (Form 3). The psychomotor adaptive skill area is included in the GAC, but not in the Adaptive Domains. The work area is optional in the forms for parents and teachers, and is only assessed if the examined person is over 17 and works full- or part-time. The psychomotor area is not included in the GAC or in the Adaptive Domains. The skill area for work, included in the form dedicated to an adult (Form 5), is only evaluated if the person assessed works full- or parttime, and when the standard result for the practical adaptive domain as well as the general result for the GAC can be calculated with or without taking into account the result for the converted area of work-related adaptive skills (Harrison \& Oakland, 2015).

In ABAS-3, each adaptive skill area has a dedicated description. For example:

1. Communication: speech, language and listening skills needed to communicate with other people (e.g. vocabulary, responding to questions, conversation skills, non-verbal communication skills),

2. Practical Learning: skills that are fundamental to reading, writing, mathematics and other skills needed for everyday independent functioning (e.g. literacy, counting, drawing simple shapes [at an earlier age] and giving the time, measuring, writing notes and letters),

3. Self-direction: skills needed for independence, responsibility and self-control (e.g. making choices, starting and finishing tasks, following a typical daily plan, following directions),

4. Leisure Time: skills needed to engage and plan leisure time and recreational activities (e.g. play with others, play with toys, engage in recreational activities at home, follow rules in games),

5. Social Life (socialisation): skills needed to interact socially and maintain contact with others (e.g. showing affection, making friends, showing and recognising emotions, helping others, showing good manners),

6. Social Functioning: skills needed to function and behave appropriately in society (e.g. move around an area, show interest in activities outside home, recognise different types of infrastructure),

7. Home/School Activities: skills needed for taking basic care for the home or place of residence, or school and classroom (e.g. cleaning, helping adults with housework or schoolwork, taking care of one's own belongings),

8. Health and Safety: skills needed to care for and respond to an illness or injury (e.g. to follow safety rules, use medication, exercise caution, avoid hazards),

9. Self-care: skills needed to take care of oneself (e.g. eating, dressing, bathing, using the toilet, shearing, hygiene),

10. Motor Skills: basic motor skills needed to move, manoeuvre in the environment, as well as the development of more complex skills, including those used in sports (e.g. basic skills such as sitting, standing, walking, proper motor control, kicking),

11. Work: skills needed to function properly and to maintain full or part-time work (including carrying out work tasks, cooperating with superiors, and following the work schedule) (see: Harrison \& Oakland, 2015).

It should be noted that in the form dedicated for parent/primary caregiver and in the form for teacher/day-care provider, work as an area of adaptive skills concerns preparation for practical learning, while in the forms for parents, teachers and adults, this area is about practical learning. In the form for parent/primary caregiver, as well as for parent and an adult person, this area is called life at home, while in the form for teacher/day-caregiver and for teacher, it is called life at school. The motor skills area is included only on the form for parent/primary caregiver and on the form for teacher/day-care 
provider. In forms for parents, teachers and adults, motor skills are evaluated only if the person examined works full- or part-time.

\section{HOW ABAS-3 DIFFERS FROM THE PREVIOUS VERSIONS}

The five ABAS-3 forms were developed from the previous version of the tool (ABAS-II), yet they include significant revisions. Thus, in order to assess more accurately the better and less developed abilities of the assessed subject, new descriptions of low-difficulty behaviours were added to the forms for infants and pre-schoolers, while new descriptions of high-difficulty behaviours were added to the school and adult forms. The existing descriptions have also been improved and new ones were added for improved assessment as regards the lack of adaptive skills associated with three types of disorders: intellectual disability (ID), autism spectrum disorders (ASD) and ADHD. Moreover, references to newer technologies and related sources - such as the Internet resources - are made, substituting previous referencing to printed encyclopaedias. Nonetheless, the overall number of descriptions in each ABAS-3 form remains the same as in the corresponding forms of the ABAS-II.

In addition to the option to conduct the assessment and evaluate the data on paper and in a stand-alone, off-line application, an on-line functionality for testing has been developed (American English language version). The dedicated online platform allows the investigator to collect all the data remotely. All the forms concerning one person can be evaluated and aggregated into a single report, which can serve as a basis for a follow-up plan, generated based on all or selected aspects of the assessment. Drawing upon the feedback from ABAS-II users, ABAS-3 has been equipped with a functionality allowing examination of the differences between assessments from two investigators on the same person, in order to determine whether the evaluation discrepancies can serve as a basis for further analysis (Harrison \& Oakland, 2015).

The investigators should have appropriate training, knowledge and experience in basic educational and psychological assessment and in interpretation of results. They are responsible for coordinating the process of completing the forms, as well as scoring and interpreting the results. As they may also be involved in decision-making based on ABAS-3 results, they should therefore comply with relevant legal and ethical standards as well as other professional and institutional requirements.

Although ABAS-3 provides a comprehensive assessment of adaptive behaviour, according to Harrison \& Oakland (2015), it should not be used as a sole instrument for diagnosing and planning a treatment for an individual. It should be used in convergence with other data sources, including information from previous or concurrent evaluations, detailed interviews and case background, records in development assessment sheets, school or workplace documents, as well as direct observation.

\section{STANDARDISATION}

ABAS-3 was standardised on a representative sample of 4500 people aged 0 to 89 , using 7737 forms completed by the investigators. The reference groups were stratified to reflect proportionately the US population on the basis of variables such as gender, ethnic group, socio-economic status, and educational level. The groups included people with normal developmental patterns and people with disabilities. Reliability was examined based on the internal consistency method, test-retest consistency, consistency of assessments and consistency of forms. Validity was examined using the method of validation of test content, factor analysis, comparison of clinical groups, equivalence with ABAS-II, and by conducting a simultaneous assessment of adaptive behaviour by means of an independent evaluation method (Harrison \& Oakland, 2015).

\section{STRENGTHS OF THE TOOL}

Investigators using ABAS-3 acknowledge the system's great advantage in its being a comprehensive assessment tool for adaptability throughout the life span, which can be generalised only for the original English version, which covers the age bracket of 0-89 years. ${ }^{1}$ The evaluation results

$1{ }^{3}$ The planned Polish adaptation of ABAS-3 foresees researching subjects in the age bracket 0-20. The release is planned for the turn of 2020 . https://www.practest.com.pl 
can be compared in different age groups or for the same individuals throughout the lifetime. What is more, all the results can be categorised descriptively (extremely high, low, below average, average, above average, high) (Harrison \& Oakland, 2015; also see: Jordan, Thomeer, Lopata, \& Donnelly, 2019; Hill et al., 2019).

Due to the short time needed to complete the questionnaire, the survey is relatively easy to carry out in numerous groups (cf. Mahendiran, Dupuis, Crosbie, Georgiades, Kelley, Liu, Nicolson, Schachar, Anagnostou, \& Brian, 2019; Košmrlj, 2018). Since ABAS-3 provides an opportunity to investigate differences between the assessments of two subjects (e.g. teacher and parent, the subject himself), possible outcomes may provide implications for clinical practice, or therapeutic work with the entire environment of the assessed person. Engaging different evaluators implies different assessment perspectives (Jordan et al., 2019).

This way of constructing the evaluation instrument - which includes the option of obtaining an overall score (GAC), the results for the three adaptive domains and for individual skills - allows for much more thorough planning of the therapeutic intervention and anticipation of the consequences of emerging developmental difficulties or the deterioration of functional skills. This is vital for clinical work (Dégeilh, Bernier, Gravel, \& Beauchamp, 2018; Ricci, 2018). ABAS-3 also allows for screening for disability, in particular for autism spectrum disorder (ASD). Its results clearly indicate lower adaptive potential of people with ASD. The negative relationship between social skills and autism is observed, regardless of the level of intelligence (Kenworthy, Case, Harms, Martin, \& Wallace, 2010).

Following the authors (Harrison \& Oakland, 2015), it should be stated that ABAS-3 generates norm-referenced scaled standard scores and the testage equivalents. The evaluated skills and domains comply with the guidelines by the American Association on Intellectual and Developmental Disabilities (AAIDD), the Diagnostic and Statistical Manual of Mental Disorders (DSM)-5, the Individuals With Disabilities Education Act (IDEA) and "Response to Intervention" (RTI) strategies to plan individual and systemic solutions. Subsequent assessments of adaptive skills are important when- ever a disorder or other condition affects the daily functioning of a student. ABAS can be used over a person's lifetime. This is why ABAS can help identify the optimal learning environment for the child or help provide independent life for an elderly person. ABAS-3 delivers information necessary to make appropriate clinical choices and to design effective individualised intervention plans. In summary, regardless of the age of the subject or the nature of his or her limitations, ABAS is an instrument that can help teachers, therapists and physicians in

1. assessing the adaptive skills of people with intellectual disabilities,

2. diagnosing and classifying disabilities and disorders,

3. identifying strengths and weaknesses,

4. documenting and monitoring progress over time,

5. developing treatment plans,

6. determining entitlement to disability benefits or related issues,

7. assessing one's ability to live or/and work as a self-directed person,

8. developing appropriate strategies to improve functioning at home, school, work and in the community,

9. developing comprehensive activities for an individual, a small group or a class, and

10. formulating suggestions for involving the teacher and family in intervention programmes.

Such comprehensive measures are possible only if the evaluation instrument allows for the examination of people between 0 and 89 years of age. They also require that the institutional system of disability assessment and the system for developing strategies for working with students with intellectual disabilities be compatible - at least to the extent foreseen in the American variant.

\section{A CRITICAL PERSPECTIVE}

A critical look at the Polish adaptation of ABAS3 makes us conclude that it lacks in user-friendliness. Initial research attempts indicate that some of the translated concepts lack clarity - especially when approached by parents. These translations sometimes fail to capture the essence of the matters in question. One needs to keep in mind that parents 
should not be expected to know specialist terminology, and that they should be able to understand all the terms and concepts on the forms. Therefore, the next edition of the tool needs a revised approach to terminology: terms used in the Polish ABAS-3 should be consulted with practitioners and parents in particular.

Each subsequent assessment of adaptive skills is important insofar as a disorder or a condition affects a student's daily functioning. The original version of ABAS-3 offers assessment throughout the whole lifespan. This is how it is possible to identify the optimal learning environment for a child or to provide an independent life for an elderly person. ABAS-3 provides information required for appropriate clinical decisions and for designing effective individualised interventions. The Polish version of the tool reaches no further than the age of 20, and this is undoubtedly its weakness, as the conducted therapy cannot be analysed in a life-long perspective. To make matters worse, the Polish adaptation does not even cover the entire education period, which - under the Polish system for people with moderate and severe intellectual disabilities - reaches the age of 24, and for severe cases even 25 .

From a purely pragmatic perspective, it should also be stated that the cost of the Polish adaptation of ABAS-3 also counts as a weakness. In order to obtain a localised Polish ABAS-3 textbook, test sheets and result comparison sheets, as well as the intervention plan, one has to reckon with an expense of over 1000 PLN (over 200 EUR). For many educational institutions and teachers this cost is a barrier. However, it must be acknowledged that the tool is well worth the price. ABAS-3 not only enables diagnosis, but also presents many possible post-diagnostic support measures. Proposals for recommended rehabilitation and training activities for all test items in the test sheets used in Adaptive Behaviour Assessment are of great value to those who support student development.

\section{CONCLUSIONS AND FUTURE DIRECTIONS}

The article presents the potential ABAS-3 as assessed from the experience of using the tool in Poland. ABAS-3 generates norm-referenced scaled results and their equivalents for the test age (Harrison \& Oakland, 2015). Skills and function domains comply with the guidelines provided by the AAIDD, DSM-5, strategies for working with students with learning difficulties, IDEA and RTI, which allows effective planning of both individual and systemic solutions.

It is to be hoped that the planned Polish edition of ABAS-3 ultimately be extended to include the full adaptation (to cover the age bracket $0-89$ of the examined persons with intellectual disability), and that the Polish health, education and social welfare systems can use the same collaboratively developed tools for the diagnosis and planned support of people with disabilities. Only then will ABAS-3 be fully applicable to the purpose for which it is developed, and the results obtained will be useful and properly applied. These advantages are available in the original tool. The presented analysis of how ABAS-3 has been applied in Poland can facilitate its use in other European countries, including Croatia. The analysis of the Polish adaptation of the tool recommends measures to maximise the usability of ABAS-3 results throughout the whole lifespan of an examined person. 


\section{REFERENCES}

Angkustsiri, K., Simon, T. J. \& Hastings, P. D. (2019). Parenting, anxiety, and adaptive function in children with chromosome 22q11.2 deletion syndrome, cambridge.org/jcts.

Atli, A., Gunuc, S. \& Kuss, D. (2019). Impact of parents' technology use on 18- to 24-month-old infants'Adaptive Behaviors. First Published May 9, https://doi.org/10.1177/1059712319845340.

Aronowitz., R. A. (1998). Making sense of illness. Science, society, and disease. Cambridge: Cambridge University Press.

Bach., M. (2007). Changing perspectives on developmental disabilities. [In:] I. Brown, \& M. Percy, (eds.): $A$ comprehensive guide to intellectual and developmental disabilities. Baltimore: Brookes, pp. 35-57.

Browder, D. M., Trela, K., Gibbs, S. L., Wakeman, S. \& Hallis, A. A. (2007). Academic skills: Reading and mathematics. [In:] S. L. Odom, R. H. Horner, M. E. Snell \& J. Blacher (eds.), Handbook of developmental disabilities, New York: Guilford Press, pp. 292-309.

Brown, I. (2007). What is meant by intellectual and developmental disabilities? [In:] I. Brown \& M. Percy (eds.): $A$ comprehensive guide to intellectual and developmental disabilities, Baltimore: Brookes, pp. 3-15.

Cooper, S. A., Smiley, E., Morrison, J., Wiliamson, A. \& Allan L. (2007). Mental ill-health in adults with intellectual disabilities: Prevalence and associated factors. British Journal of Psychiatry, No. 190, pp. 27-35.

Dégeilh, F., Bernier, A., Gravel, J. \& Beauchamp, M. H. (2018). Developmental trajectories of adaptive functioning following early mild traumatic brain injury, Dev Psychobiol. 2018 Dec; 60(8):1037-1047.

Denning, C. B., Chamberlain, J. A. \& Polloway, E. A. (2000). An evaluation of state guidelines for mental retardation: Focus on definition and classification practices. Education and Training in Mental Retardation and Developmental Disabilities, 35, pp. 226-232.

Diagnostic and statistical manual of mental disorders fifth edition DSM-5 ${ }^{T M}$, American Psychiatric Association, Washington, DC London, England, 2013.

Douma, J., Dekker, M. C., Ruiter, K. S., Tick, N. T. \& Koot, H. M. (2007). Antisocial and delinquent behaviors in youths with mild or borderline disabilities. American Journal on Mental Retardation, No. 112, pp. 207-220.

Dunst, C. J., Bruder, M. B., Trivette, C. M. \& Hamby, D. W. (2006). Everyday activity settings, natural learning environments, and early intervention practice. Journal of Policy and practice in Intellectual Disabilities, No. 3 , pp. 3-10.

Eby, N. S., Griffith, J. L. Gutmann, D. H. \& Morris S. M. (2019). Adaptive functioning in children with neurofibromatosis type 1: relationship to cognition, behavior, and magnetic resonance imaging. Developmental Medicine \& Child Neurology, Volume 61, Issue 8, pp. 972-978.

Finlay, W. M. L. \& Lyons, E. (2005). Rejecting the label: A social constructionist analysis. Mental Retardation, 43, pp. 120-134.

Goodey, C. F. (2006). Behavioural phenotypes in disability research: Historical perspectives. Journal of Intellectual Disability Research, No. 50 (6), pp. 397-403.

Gottfredson, L. S., (1997). Mainstream science on intelligence: An editorial with 52 signatories, history, and bibliography. Intelligence, No. 24 (1), pp. 13-23.

Grossman, H.J. (1983). Classification in mental retardation. American Association on Mental Retardation. Washington, DC.

Hansen, L. A. (2019). Concurrent validity study of the Missouri adaptive ability scale and the adaptive behavior assessment system, third edition - teacher form Murray State Theses and Dissertations. 149. https://digitalcommons. murraystate.edu/etd/149. 
Harrison, P.L. \& Oakland, Th. (2000). Adaptive behavior assessment system. San Antonio, TX: Psychological Corporation.

Harrison, P.L. \& Oakland, Th. (2003). Technical report: Adaptive behavior assessment system. San Antonio, TX: Psychological Corporation.

Harrison, P.L. \& Oakland, T. (2015). Adaptive Behavior Assessment System, Third Edition [Manual]. Torrance, CA: Western Psychological Services.

Harrison, P.L. \& Oakland, T. (2015). ABAS®-3) Adaptive Behavior Assessment System, Third Edition, https://www. centilepsych.ph/wp-content/uploads/2017/11/special-education-test-detailed.pdf.

Hayden, M. F. \& Nelis, T. (2002). Self-advocacy. [In:] R. L. Schalock, P. C. Baker, \& M. D. Croser (eds.), Embarking on a new century: Mental retardation at the end of the 20th century (pp. 221-234). Washington, DC: American Association on Mental Retardation.

Hays, L. H. (2018). Self-Reported Self-Management of Adults With Congenital Heart Disease, Circulation. 2018;138:A15016.

Hill D., Gore, C. \& Lee S. (2019). C-58 Reliable Change Index to Monitor Executive, Adaptive and Behavioral Functioning in Children with Perinatal Complications, Archives of Clinical Neuropsychology, Volume 34, Issue 6, August 2019, Page 1087, https://doi.org/10.1093/arclin/acz034.220.

Institute of Medicine. (1991). Disability in America: Towards a national agenda for prevention. Washington, DC: National Academy Press.

Jordan, A.K., Thomeer, M.L., Lopata, C. \& Donnelly, J.P (2019). Informant Discrepancies in the Assessment of Adaptive Behavior of Children with Autism Spectrum Disorder, Journal of Autism and Developmental Disorders May 2019, Volume 49, Issue 5, pp. 2024-2034.

Kirenko, J. \& Łaba-Horecka, A. (2018). Niepetnosprawność intelektualna - Wyuczona bezradność - Uwarunkowania. Wydawnictwo Uniwersytetu Rzeszowskiego. Rzeszów.

Kenworthy, L., Case, L. Harms, M. B., Martin, A. \& Wallace, G. L. (2010). Adaptive Behavior Ratings Correlate With Symptomatology and IQ Among Individuals With High-Functioning Autism Spectrum Disorders, Journal of Autism and Developmental Disorders, April 2010, Volume 40, Issue 4, pp. 416-423.

Kostrzewski, J. (1997). Ewolucja poglądów AAMR dotyczących niedorozwoju umysłowego. Od Rocka Hebera (1959) do Ruth Luckasson i in. (1992). [In:] Roczniki Pedagogiki Specjalnej. Ed. by J. Pańczyk. Vol. 8. WSPS, Warszawa, pp. 210-233.

Kostrzewski, J. (2006). Niepełnosprawność umysłowa: poglądy, metody diagnozy i wsparcia. [In:] A. Czapiga (ed.), Psychologiczne wspomaganie rozwoju psychicznego dziecka. Wrocław: WTN.

Košmrlj, L. (2018). Prilagoditvene spretnosti, čustvene in vedenjske težave pri otrocih in mladostnikih z živčnomišičnimi boleznimi, repozitorij.uni-lj.si.

Kuhn, J., Hickey, E., Broder-Fingert \& S., Crossman, M., (2019). Service and Intervention Impacts on Parenting Stress in Low-income and Minority Families of Children with Autism Spectrum Disorder, Gatlinburg Conference Poster Submission, PS-22.

Li, L., Zhao, Js., Gao, ZF., Ma, Cy., Dong, CH. \& Zhang, HW. (2019). Application of apparent diffusion coefficient in children aged 2-12 years with intellectual disability/global developmental delay who have normal conventional brain MRI findings; Zhongguo Dang dai er ke za zhi = Chinese Journal of Contemporary Pediatrics, 01 Jun 2019, 21(6):541-546.

Luckasson, R., Coulter, D. L., Polloway, E. A., Reese, S., Schalock, R. L., Snell, M. E., Spitalnik, D. M. \& Stark, J. A. (1992). Mental retardation: Definition, classification, and systems of supports (9th ed.). Washington, DC: American Association on Mental Retardation; WHO - 2001). 
Luckasson, R., Borthwick-Duffy, S., Buntinx, W. H. E., Coulte,r D. L., Craig, E. M., Reeve, A., Schalock, R. L., Snell, M. E., Spitalnik, D. M., Spreat, S. \& Tasse, M. J. (2002). Mental retardation: Definition, classification, and systems of supports (10th ed.). Washington, DC: American Association on Mental Retardation.

Luckasson, R. \& Reeve, A. (2001). Naming, defining, and classifying in mental retardation. Mental Retardation, 39, pp. 47-52. Meijer M.M. et al. 2004.

Mahendiran, T. Dupuis, A., Crosbie, J., Georgiades, S., Kelley, E., Liu, X., Nicolson, R., Schachar, R., Anagnostou, E. \& Brian, J., (2019). Sex Differences in Social Adaptive Function in Autism Spectrum Disorder and AttentionDeficit Hyperactivity Disorder, Front Psychiatry. 2019 Sep 12;10:607.

Myrbakk, E. \& von Tetzchner, S. (2008). Screening individuals with intellectual disability for psychiatric disorders: Comparison of four measures. American Journal on Mental Retardation, No. 113, pp. 54-70.

Neisser, U., Boodoo, G., Bouchard, T. J., Wade Boykin, A., Brody, N., Ceci, S. J., Halpern, D. F., Loehlin, J. C., Perloff, R., Sternberg, R. J. \& Urbina, S. (1996). Intelligence: Knows and unknowns. American Psychologist, No. 51, pp. 77-101.

Patton, J. R. \& Keyes, D. (2006). Death penalty issues following Atkins. Exceptionality, No 14, pp. 237-255.

Perske, R. (2005). Strange shift in the case of Daryl Atkins, Mental Retardation, No. 43, pp. 454-455.

Perske, R. (2008). False confessions from 53 persons with intellectual disabilities: The list keeps growing. Intellectual and Developmental Disabilities, No. 46, pp. 468-479.

Polloway, E. A., Lubin, J., Smith, J. D. \& Patton, J. R., (2010). Mild Intellectual Disabilities: Legacies and Trends in Concepts and Educational Practices, Education and Training in Autism and Developmental Disabilities, No. 45 (1), pp. 54-68.

Polloway, E. A., Patton, J. R., Smith, J. D.., Antoine, K. \& Lubin, J. (2009). State guidelines for mental retardation and intellectual disabilities: A revisitation of previous analyses in light of changes in the field. Education and Training in Developmental Disabilities, No. 44, pp.14- Rapley M. (2004): The social construction of intellectual disability. Cambridge, UK: Cambridge University Press.

Ricci, M. F. et al. (2018). Deterioration of functional abilities in children surviving the Fontan operation, Cardiol Young. 2018 Jun;28(6):868-875.

Schalock, R. L., Luckasson, R. A., Shogren, K. A., Borthwick-Duffy, S., Bradley, V., Buntinx, W. H., Coulter, D.L., Craig, E. M., Gomez, S.C., Lachapelle, Y., Reeve, A., Snell, M. E., Spreat, S., Tassé, M. J., Thompson, J. R., Verdugo, M. A., Wehmeyer, M. L. \& Yeager, M. H. (2007). The renaming of mental retardation: understanding the change to the term intellectual disability, Intellectual and Developmental Disabilities, No. 45 (2), pp. 116-124.

Schalock, R.L., Borthwick-Duffy, S.A., Bradley, V.J., Buntinx, W.H.E., Coulter, D.L., Craig, E.M., Gomez, S.C., Lachapelle, Y., Luckasson, R., Reeve, A., Shogren, K.A., Snell, M.E., Spreat, S., Tassé, M.J., Thompson, J.R., Verdugo-Alonso, M.A., Wehmeyer, M.L. \&Yeager, M.H. (eds.) (2010). Intellectual disability. Definition, Classification and Systems of Supports, The $11^{\text {th }}$ edition of the AAIDD Definition Manual, American Association on Intellectual and Developmental Disabilities, Washington, DC.

Slim, M. et al. (2019). The Association Between Sleep Related Breathing Disorders and Neuropsychological Function in Pediatric, Stroke February 2019 - Volume 50, Issue Suppl_1: Abstracts From the American Heart Association/ American Stroke Association 2019 International Stroke Conference and State-of-the-Science Stroke Nursing Sym.

Snell, M. E. \& Voorhees, M. D. (2006). On being labeled with mental retardation. [In:] H. N. Switzky, S. Greenspan (eds.), What is mental retardation: Ideas for an evolving disability (pp. 61-80). Washington, DC: American Association on Mental Retardation.

Sparrow, S.S. \& Cicchetti, D.V. (1985). Diagnostic uses of the Vineland Adaptive Behavior Scales. "Journal of Pediatric Psychology”. No. 10(2) pp. 215-225. 
Szakács, A., Chaplin, J. E., Tideman, P., Strömberg, U., Nilsson, J., Darin, N. \& Hallböök, T. (2019). A populationbased and case-controlled study of children and adolescents with narcolepsy: Health-related quality of life, adaptive behavior and parental stress. European Journal of Paediatric Neurology Volume 23, Issue 2, March 2019, pp. 288-295.

Udhnani, M., Perez, M. \& Lee, N. R. (2019). Predictors of Individual Differences in Language Abilities in Youth with Neurodevelopmental Disorders: Examining the Executive Function and Social Correlates of Structural and Pragmatic Language in Down Syndrome and Autism Spectrum Disorder, Gatlinburg Conference Poster Submission, PS-22.

Witkowski, T. (1997). By podnieść poziom społecznego funkcjonowania osób z upośledzeniem umystowym. Wydawnictwo FŚCEDS, Lublin.

Wotherspoon, J. M., Eagleson, K. J., Gilmore, L., Auld, B., Hirst, A., Johnson, S., Stocker, C., Heussler, H. \& Justo, R. N. (2019). Neurodevelopmental and health-related quality-of-life outcomes in adolescence after surgery for congenital heart disease in infancy, Developmental Medicine \& Child Neurology, Volume 62, Issue 2 February 2020, pp. 214-220.

Zukermana. G., Yahava. G. \& Ben-Itzchak. E. (2019). Increased psychiatric symptoms in university students with autism spectrum disorder are associated with reduced adaptive behavior. Psychiatry Research, Volume 273, March 2019, pp. 732-738. 